Research Article

\title{
Refined Vehicle-Bridge Interaction Analysis Using Incompatible Solid Finite Element for Evaluating Stresses and Impact Factors
}

\author{
Qing Xie $\mathbb{D D}^{1}{ }^{1}$ Wanshui Han $\mathbb{D}^{1},{ }^{1}$ and Yangguang Yuan $\mathbb{D}^{2}$ \\ ${ }^{1}$ School of Highway, Chang'an University, Xi'an, Shaanxi 710064, China \\ ${ }^{2}$ School of Civil Engineering, Xi'an University of Architecture and Technology, Xi'an, Shaanxi 710055, China \\ Correspondence should be addressed to Wanshui Han; hws@gl.chd.edu.cn
}

Received 25 June 2019; Accepted 9 December 2019; Published 13 March 2020

Academic Editor: Claudio Mazzotti

Copyright (c) 2020 Qing Xie et al. This is an open access article distributed under the Creative Commons Attribution License, which permits unrestricted use, distribution, and reproduction in any medium, provided the original work is properly cited.

The vehicle-bridge interaction can induce bridge vibration and consequently fatigue, durability deterioration, local damage, and even collapse of bridge structure. In this paper, a solid vehicle-bridge interaction (VBI) analysis method is developed to provide refined analysis on the bridge responses including displacement and local stress under vehicle loads. The incompatible solid finite element (FE) is introduced to model the bridge, where the element shear locking is alleviated by incompatible displacement modes without sacrificing the computational efficiency. Benchmark example shows the incompatible solid element has superior computational efficiency compared to the conventional solid element. By virtue of the mass-spring-damper vehicle model, the interaction between vehicle and bridge is simulated with point-to-point contact assumption and the coupled dynamic equations are solved via nonlinear iteration. A case study on a simply supported T-girder bridge is conducted to validate the developed solid VBI analysis method and then the dynamic impact factor (DIF) of the bridge is evaluated based on the computed stress results and compared to code values. Results show that the solid VBI analysis method yields more accurate time-history bridge responses including displacement and stress under moving vehicles than the grillage method despite higher computational cost. Particularly, it can simulate realistic stress distribution and concentration along any concerned sections as well as in local components, which can provide detail information on the bridge behavior under dynamic loads. On the other hand, the DIF based on the computed stress result generally agrees well with the code values except for heavy vehicles where the stress-based DIF is slightly higher than the value in Chinese code while lower than that of AASHTO, suggesting the value specified by Chinese code may underestimate the DIF of heavy vehicles in certain circumstances to which more attention should be paid.

\section{Introduction}

The in-service bridges are subjected to moving vehicles every day and the dynamic interactions between vehicles and bridges can, on one hand, induce the bridge vibration and consequently the fatigue, durability deterioration, local damage, and even collapse of the bridge structure and on the other hand, lead to the influence on the vehicle safety as well as passengers' comfort. As a result, the vehicle-bridge interaction (VBI) has been extensively studied in the past few decades. It is well accepted that VBI is influenced by many factors including the bridge structure (e.g., span length and natural frequency), road surface roughness, vehicle suspension system, vehicle weight and vehicle speed, etc. Due to the complexity of VBI problem and the high cost of field test including difficulties in data collection, numerical VBI analyses have been widely employed to investigate bridge behaviors under dynamic vehicle loads [1-4].

Most numerical VBI analyses are based on the finite element method (FEM), in which the bridges are modeled by different types of element such as beam element, plate/shell element and solid element. In the beam-based bridge models $[3,4]$, the bridge is simplified as a beam axis or a grillage with cross-sectional properties assigned to each beam element. They have the superiorities of simplicity and high computational efficiency [5]. Nevertheless, as the beam element yields the nodal displacement and the internal force on the cross-section that the node correspondingly represents, stress distributions on the cross-section cannot be obtained straightforward. Thus, these models are usually preferred 
particularly in long-span vehicle-bridge analysis to analyze the overall performance of bridge structure. In plate/shell bridge models $[6,7]$, thin plate/shell theories neglecting the out-of-plane normal and shear strains are assumed; thus, the complete stress-state of the modeled structure cannot be pictured. Meanwhile, as plate/shell elements approximate the bridge deck by its mid-surface, other element types are needed for non-plate components such as the girders and piers, which induces additional constraints on the structure interface $[8,9]$.

Recently, with the advances in computer technologies, sophisticated bridge models using three-dimensional (3D) solid finite elements have been developed and applied into VBI analyses [10-12]. The solid element has three translational degrees of freedom (DOFs) per node and can be used to model structures of any geometry. With 3D kinematic, constitutive and equilibrium equations, it is possible to completely describe the spatial behaviors of the structure and produce stress distributions. Besides, as solid element does not involve any rotational DOF like beam and plate/ shell elements, cumbersome updating of rotational DOFs and convergence difficulties in nonlinear analyses are circumvented [13]. Most of the solid bridge models in VBI analyses are built in commercial finite element (FE) software, e.g., ANSYS and ABAQUS. The modal superposition technique, approximating the displacement by linear combination of vibration modes, is used to calculate the bridge response which is then inputted into VBI analysis [12]. This can significantly improve the computational efficiency; however, the simulation accuracy may be limited since only those lower-order modes are mainly combined. Besides, it is also worth mentioning that the modal synthesis method cannot be directly extended to nonlinear analysis of bridges. On the other hand, Kwasniewski et al. [10] developed a solid VBI model in which a solid bridge FE model, a detailed truck FE model and their couple vibration analysis are all implemented in LS-DYNA. Nevertheless, when more types of vehicles are simultaneously travelling on the bridge, the number of DOFs in the model would increase dramatically, causing excessive computational cost.

In this paper, a refined VBI analysis method is developed. The incompatible eight-node hexahedral (H8) element free of shear locking is used to model the bridge so that fewer elements are required along the bridge thickness to save the computational cost. The vehicle is represented as a multiaxle mass-spring-damper system which can model different types of vehicles with different number of axles. The pointto-point contact is assumed at the bridge-vehicle interface and the VBI dynamic equations are solved through a nonlinear iteration. The proposed solid VBI analysis method is expected to accomplish the transient displacement and stress analysis of bridges under moving vehicles. The paper is organized as follows: firstly, a solid VBI model is established, including the solid bridge FE model, the vehicle model, the vehicle-bridge coupling and the solution method; then, a case study of a simply supported T-girder bridge is conducted to validate the VBI analysis method; finally, it is applied to investigate the dynamic impact factors (DIFs) of the bridge under random traffic flow.

\section{Refined Solid Vehicle-Bridge Interaction Model}

2.1. Solid Finite Element Model. As lower-order elements are normally more inclined in engineering analyses due to their low construction cost [14], the trilinear H8 element portrayed in Figure 1 is selected to model the bridge structure. The mapping between the global Cartesian coordinates $(x, y$, $z$ ) and the natural coordinates $(\xi, \eta, \zeta)$ is expressed as

$$
\left\{\begin{array}{lll}
x & y & z
\end{array}\right\}^{T}=\sum_{i=1}^{8} N_{i}(\xi, \eta, \zeta)\left\{\begin{array}{lll}
x_{i} & y_{i} & z_{i}
\end{array}\right\}^{T},
$$

in which $\left(x_{i}, y_{i}, z_{i}\right)$ and $\left(\xi_{i}, \eta_{i}, \zeta_{i}\right)$ are, respectively, the global coordinate and the natural coordinate of the $i$-th node and $N_{i}$ $(\xi, \eta, \zeta)=\left(1+\xi_{i} \xi\right)\left(1+\eta_{i} \eta\right)\left(1+\zeta_{i} \zeta\right) / 8$ is the three-dimensional trilinear interpolation function.

The isoparametric interpolation for the displacement of H8 element is as usual

$$
\mathbf{u}_{d}=\left\{u_{d} v_{d} w_{d}\right\}^{T}=\sum_{i=1}^{8} N_{i}\left\{u_{i} v_{i} w_{i}\right\}^{T}=\mathbf{N d}
$$

where $\mathbf{N}=\left[N_{1} \mathbf{I}_{3} N_{2} \mathbf{I}_{3} \ldots N_{8} \mathbf{I}_{3}\right]^{T}$ is the interpolation matrix and $\mathbf{d}=\left\{\begin{array}{llll}u_{1} v_{1} w_{1} & u_{2} v_{2} w_{2} & \ldots & u_{8} v_{8} w_{8}\end{array}\right\}^{T}$ is the element nodal displacement vector. The infinitesimal element strain is

$$
\boldsymbol{\varepsilon}=\left\{\begin{array}{llllll}
\varepsilon_{x} & \varepsilon_{y} & \varepsilon_{z} & \gamma_{y z} & \gamma_{z x} & \gamma_{x y}
\end{array}\right\}^{T}=\mathbf{L u}_{d}=\mathbf{B d},
$$

in which $\mathbf{L}$ is the strain-displacement operator; $\mathbf{B}=\mathbf{L N}$ is the strain-displacement matrix. For homogenous, isotropic, and linear elastic materials, the stress-strain relation fulfills the generalized Hooke's Law, namely,

$$
\sigma=\mathrm{C} \varepsilon,
$$

in which $\mathbf{C}$ denotes the constitutive matrix. Based on the principle of minimum potential energy, the element stiffness matrix of the conventional $\mathrm{H} 8$ element is written as

$$
\mathbf{K}_{d}^{\mathrm{e}}=\int_{\Omega^{\mathrm{e}}} \mathbf{B}^{T} \mathbf{C B d} \Omega,
$$

in which $\Omega$ and $\Omega^{\mathrm{e}}$ denote the problem domain and the element domain, respectively. This conventional H8 element is denoted as $\mathrm{CH} 8$.

It is a well-known concern when the first-order elements are applied to model the structure with dominating bending deformation, undesired locking phenomena would be induced and result in excessively rigid response of the structure [15]. Numerous measures such as the mesh refinement, higher-order elements, reduced integration, nonconforming FE formulation and hybrid FE formulation have been proposed to eliminate the locking deficiency [16]. Among them, the non-conforming FE formulation in which the incompatible displacement modes are assumed by introducing internal DOFs is well accepted as it can considerably improve the element accuracy neither causing element instability nor sacrificing computational efficiency. For $\mathrm{H} 8$ element, the incompatible displacement modes proposed by Wilson et al. [17] are as follows: 

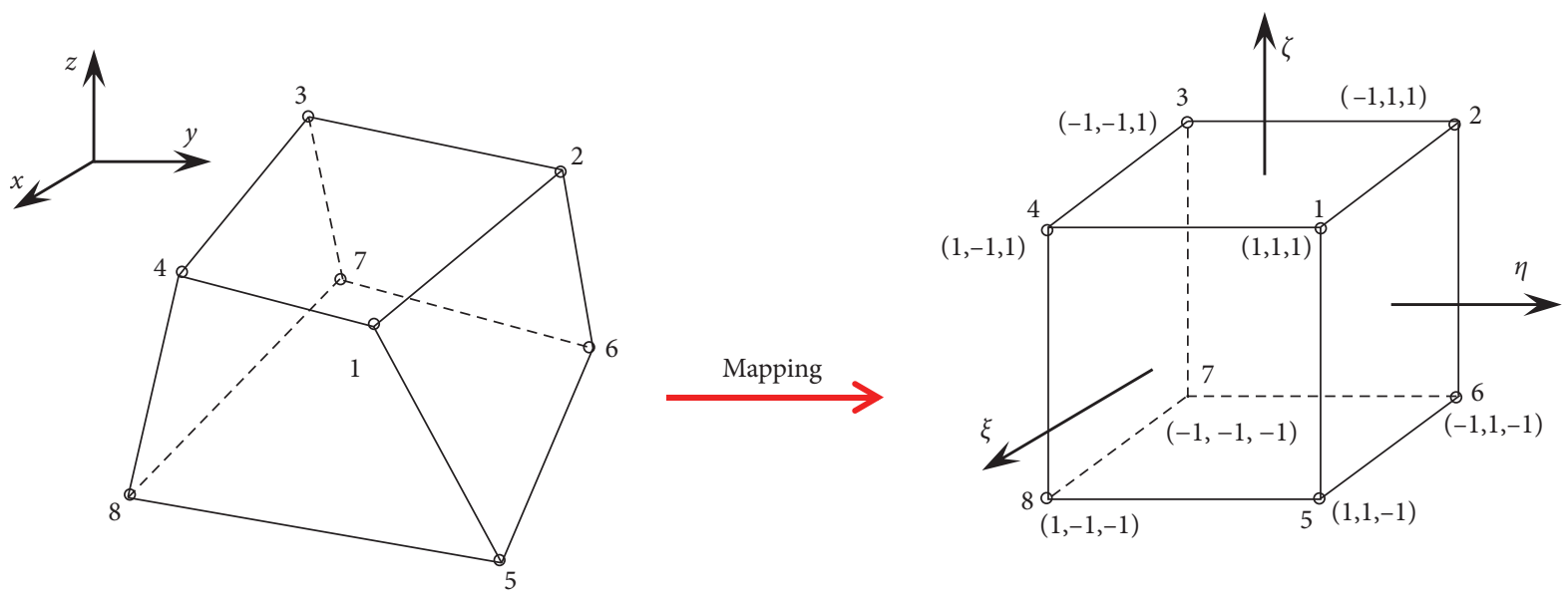

Figure 1: Eight-node hexahedral element.

$$
\begin{aligned}
\mathbf{u}_{\lambda} & =\left\{\begin{array}{lll}
u_{\lambda} & v_{\lambda} & w_{\lambda}
\end{array}\right\}^{T}=\left[\left(1-\xi^{2}\right) \mathbf{I}_{3}\left(1-\eta^{2}\right) \mathbf{I}_{3}\left(1-\zeta^{2}\right) \mathbf{I}_{3}\right]\left\{\lambda_{1} \cdots \lambda_{9}\right\}^{T} \\
& =\overline{\mathbf{N}} \lambda
\end{aligned}
$$

in which $\lambda_{i}$ denotes the assumed internal DOFs in the element and $\overline{\mathbf{N}}$ and $\boldsymbol{\lambda}$ are self-defined. With equations (2) and (6), the element displacement is enhanced as

$$
\mathbf{u}=\left\{\begin{array}{lll}
u & v & w
\end{array}\right\}^{T}=\mathbf{u}_{d}+\mathbf{u}_{\lambda}=\mathbf{N d}+\overline{\mathbf{N}} \lambda
$$

and recalling equation (3) the element strain becomes

$$
\boldsymbol{\varepsilon}=\mathbf{L u}=\mathbf{B d}+\overline{\mathbf{B}} \boldsymbol{\lambda},
$$

accordingly, in which $\overline{\mathbf{B}}=\mathbf{L} \overline{\mathbf{N}}$ is the strain-incompatible displacement matrix. Following the usual treatment in [17], the element stiffness matrix of the incompatible $\mathrm{H} 8$ element is expressed as

$$
\mathbf{K}^{\mathrm{e}}=\mathbf{K}_{d d}-\mathbf{K}_{d \lambda} \mathbf{K}_{\lambda \lambda}^{-1} \mathbf{K}_{\lambda d}
$$

in which

$$
\begin{aligned}
& \mathbf{K}_{d d}=\int_{\Omega^{\mathrm{e}}} \mathbf{B}^{T} \mathbf{C} \mathbf{B} \mathrm{d} \Omega, \\
& \mathbf{K}_{d \lambda}=\mathbf{K}_{\lambda d}^{T}=\int_{\Omega^{\mathrm{e}}} \mathbf{B}^{T} \mathbf{C} \overline{\mathbf{B}} \mathrm{d} \Omega, \\
& \mathbf{K}_{\lambda \lambda}=\int_{\Omega^{\mathrm{e}}} \overline{\mathbf{B}}^{T} \mathbf{C} \overline{\mathbf{B}} \mathrm{d} \Omega .
\end{aligned}
$$

It should be mentioned that the above element stiffness matrix only corresponds to the compatible displacement DOFs, $\mathbf{d}$, whilst the incompatible displacement parameters, $\lambda$, have been statically condensed out at the element level. This incompatible H8 element is denoted as ICH8.

To show the accuracy and efficiency of ICH8 over $\mathrm{CH} 8$, a simply supported concrete plate with dimension $10 \mathrm{~m} \times 10 \mathrm{~m} \times 0.5 \mathrm{~m}$ is considered. The material parameters of the concrete are $E=3.0 \times 10^{4} \mathrm{MPa}, v=0.2$ and $\rho=2 \times 10^{3} \mathrm{~kg} / \mathrm{m}^{3}$. The central deflection and the normal stress at top center of the plate subjected to self-weight are predicted using $\mathrm{CH} 8$ and $\mathrm{ICH} 8$, respectively. In order to check whether the element suffers from shear locking, a single-layer mesh is designed along the thickness direction whilst different mesh densities of $N \times N$ elements are adopted for in-plane directions. The predicted central deflections and normal stresses are normalized by the thin-plate solutions [18] and plotted in Figure 2. It can be seen that ICH8 performs far better than $\mathrm{CH} 8$ for both deflection and stress predictions. For example, with the mesh density of $8 \times 8$, ICH 8 produces the normalized deflection and stress about 0.92 and 0.96 whilst those of the latter are only about 0.43 and 0.59 , respectively. ICH8 is validated to possess immunity to shear locking and superior accuracy for both deflection and stress predictions with coarser mesh compared to $\mathrm{CH} 8$. Therefore, the ICH8 element is selected to model the bridge, which can save considerable computational cost without sacrificing accuracy.

2.2. Vehicle-Bridge Coupling. The vehicle is represented as a multi-axle mass-spring-damper system with many DOFs depending on the number of axles. Taking the three-axle truck model in Figure 3 as an example [19], $Z_{\mathrm{vr}}, \Phi_{\mathrm{vr}}$, and $\theta_{\mathrm{vr}}$ are, respectively, the vertical displacement, roll (rotation about the longitudinal axis or $x$-axis), and pitch (rotation about the transverse axis or $y$-axis) of the vehicle body, whilst $Z_{v a L}^{i}$ and $Z_{v a R}^{i}$ denote the vertical displacement of the left and the right wheel of $i$-th axle $(i=1,2,3)$, respectively. The equation of motion for the vehicle is expressed as

$$
\mathbf{M}_{v} \ddot{\mathbf{u}}_{v}+\mathbf{C}_{v} \dot{\mathbf{u}}_{v}+\mathbf{K}_{v} \mathbf{u}_{v}=\mathbf{F}_{v g}+\mathbf{F}_{v b},
$$

where $\mathbf{M}_{v}, \mathbf{C}_{v}$ and $\mathbf{K}_{v}$ are, respectively, the mass, damping and stiffness matrices of the vehicle; $\mathbf{u}_{v}$ is the vector of the vehicle's DOF; and $\mathbf{F}_{v g}$ and $\mathbf{F}_{v b}$ are the self-weight of the vehicle and the wheel-bridge contact force acting on the vehicle, respectively; as usual, the single over-dot and double over-dots denote, respectively, the first- and second-order time derivatives of the quantity below them.

For the bridge FE model using ICH8 elements, the equation of motion is expressed as

$$
\mathbf{M}_{b} \ddot{\mathbf{u}}_{b}+\mathbf{C}_{b} \dot{\mathbf{u}}_{b}+\mathbf{K}_{b} \mathbf{u}_{b}=\mathbf{F}_{b g}+\mathbf{F}_{b v}
$$




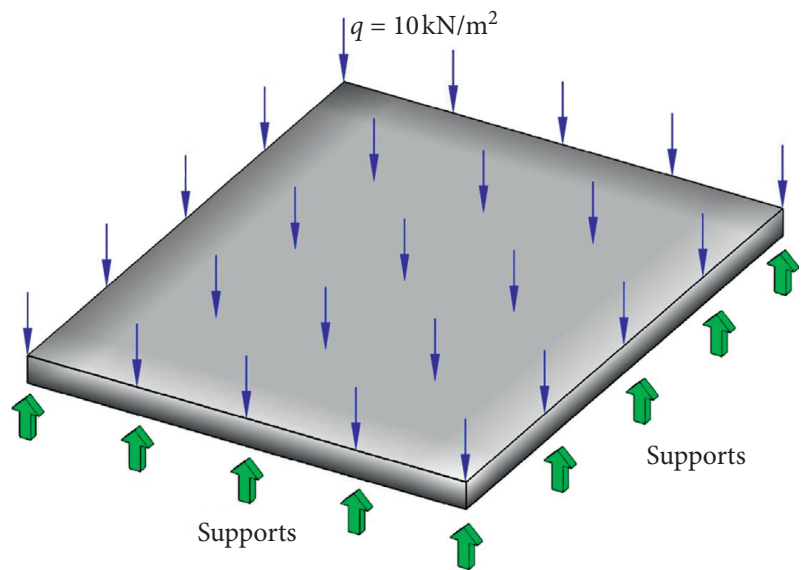

(a)

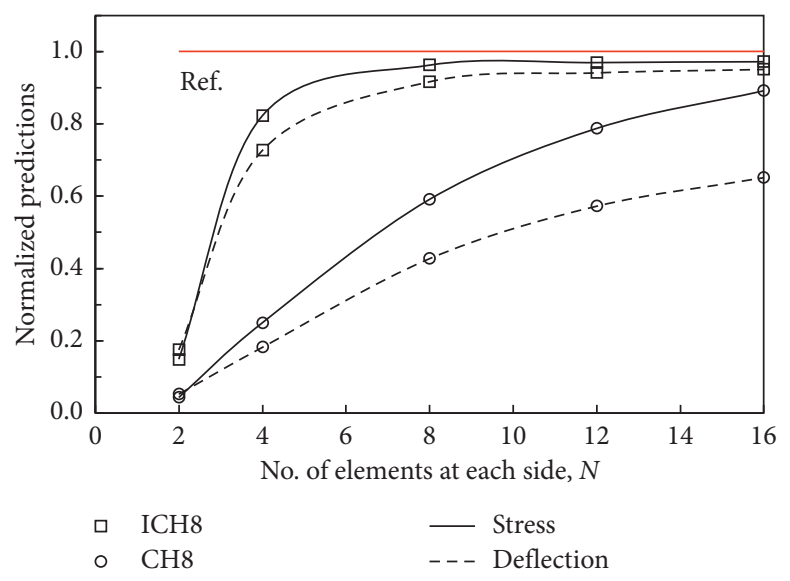

(b)

Figure 2: A simply supported concrete plate problem. (a) Dimension, load, and boundary conditions; (b) normalized displacement and stress results.
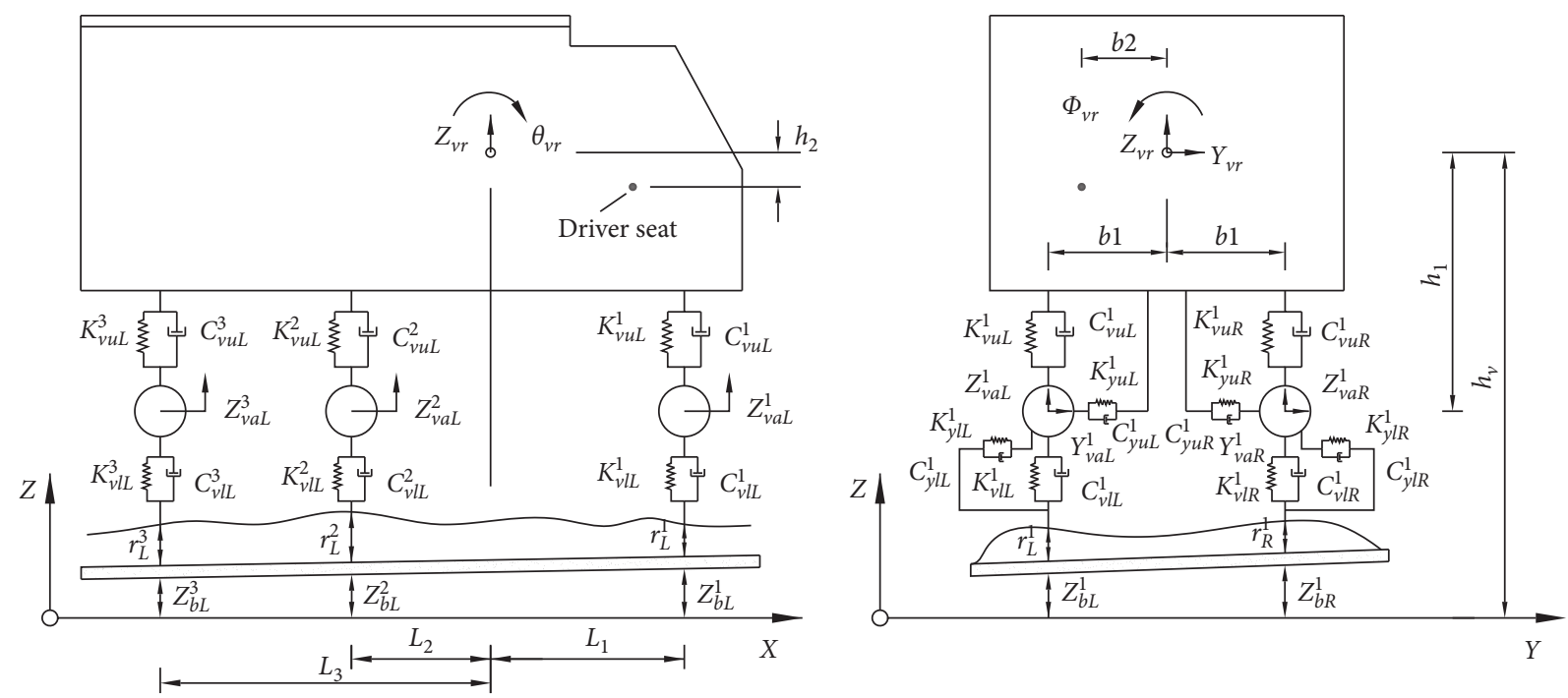

Figure 3: Three-axle vehicle model.

where $\mathbf{M}_{b}, \mathbf{C}_{b}$, and $\mathbf{K}_{b}$ are, respectively, the mass, damping and stiffness matrices of the bridge model and $\mathbf{u}_{b}$ is the bridge DOF vector; $\mathbf{F}_{b g}$ and $\mathbf{F}_{b v}$ are the self-weight of the bridge and the wheel-bridge contact forces acting on the bridge deck, respectively.

To establish the vehicle-bridge coupling relations, three hypotheses are made between the road surface and the vehicle: (1) the contact between bridge and vehicle is pointto-point contact; (2) the tires of vehicle remain in contact with the bridge deck throughout; (3) there is no sliding of vehicle tires over the bridge. Without losing generality, assume that the left (right) wheel of the $j$-th axle of the vehicle is contacting with the $k$-th solid element of the bridge deck at point $C$, as shown in Figure 4 . The vertical forces imposed by the left (right) wheel of the $j$-th axle of the vehicle on the bridge deck can be expressed as

$$
\begin{aligned}
F_{v L(R)}^{j}= & K_{v l L(R)}^{j}\left(Z_{v a L(R)}^{j}-Z_{b L(R)}^{j}-r_{L(R)}^{j}(x)\right) \\
& +C_{v l L(R)}^{j}\left(\dot{Z}_{v a L(R)}^{j}-\dot{Z}_{b L(R)}^{j}-\dot{r}_{L(R)}^{j}(x)\right),
\end{aligned}
$$

where $K_{v l L(R)}^{j}$ and $C_{v l L(R)}^{j}$ are the lower spring stiffness coefficient and damping coefficient of the left (right) wheel of the $j$-th axle of the vehicle, respectively; $r_{L(R)}^{j}(x)$ is the road surface roughness, taken as a function of the longitudinal position, $x$, of the contact point when the vehicle is running straight along the longitudinal direction; and $\dot{r}_{L(R)}^{j}(x)=\left(\mathrm{d} r_{L(R)}^{j}(x) / d x\right) \cdot(\mathrm{d} x / d t)=\mathrm{d} r_{L(R)}^{j}(x) / \mathrm{d} x \cdot V(t)$ 

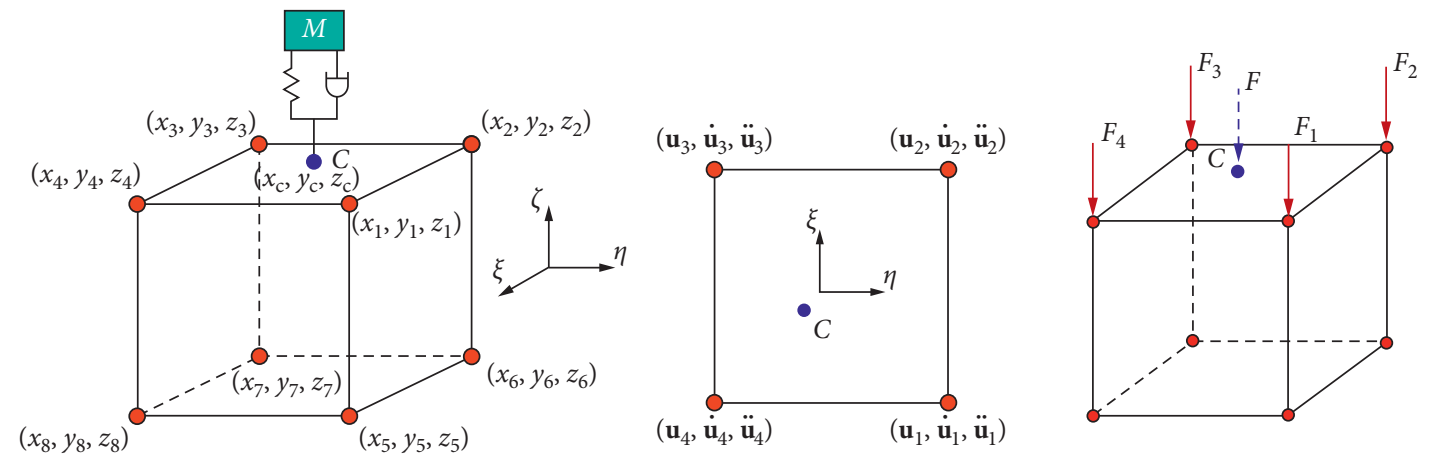

Figure 4: Transfer of variables at the tire-bridge deck contact interface.

and $V(t)$ is the vehicle velocity. It should be noted that the measured road roughness condition which will be introduced later is employed in the present study. In equation (13), $Z_{b L(R)}^{j}$ is the vertical displacement of the bridge at the contact point $C$ and determined through the interpolation relation of ICH8 as

$$
Z_{b L(R)}^{j}=\sum_{n=1}^{4} L_{n}\left(\xi_{C}^{k}, \eta_{C}^{k}\right) Z_{b n}^{k}
$$

in which $L_{n}(\xi, \eta)=\left(1+\xi_{n} \xi\right)\left(1+\eta_{n} \eta\right) / 4$ and $Z_{b n}^{k}$ are the interpolation function and vertical displacement of the $n$-th node at contact surface of element $k$, respectively; $\left(\xi_{C}^{k}, \eta_{C}^{k}\right)$ is the natural coordinate of contact point $C . \dot{Z}_{b L(R)}^{j}$ can be obtained through similar interpolation.

The vertical contact force exerted by the left (right) wheel of the $j$-th axle of the vehicle is distributed to the bridge deck through the nodal forces at the contact surface of element $k$ as

$$
F_{b v n}^{k}=L_{n}\left(\xi_{C}^{k}, \eta_{C}^{k}\right) F_{v L(R)}^{j},
$$

in which $F_{b v n}^{k}$ is the vertical contact force distributed to the $n$-th node at contact surface of element $k$. Similarly, the vertical contact force by all axles of all vehicles is obtained and assembled to get the global wheel-bridge contact force applied on the bridge, $\mathbf{F}_{b v}$.

To solve the coupled vehicle-bridge model indicated in equations (11)-(15), the bridge and the vehicle equations are established independently as in equation (11) and equation (12), and then solved separately through a nonlinear iterative procedure in each time step according to the displacement compatibility and force equilibrium conditions at the vehicle-bridge contact interface. The main procedures for solving the VBI model are as follows:

\section{(i) Input basic data of the VBI model:}

For bridge: geometric and material parameters, bridge FE model, and road surface roughness of the bridge deck.

For vehicle: vehicle classifications, vehicle occupancy, and vehicle speed.

(ii) Determine the number and positions of all vehicles travelling on the bridge and combine the road roughness and deck movements $\left(\ddot{\mathbf{u}}_{b}^{t-1}, \dot{\mathbf{u}}_{b}^{t-1}, \mathbf{u}_{b}^{t-1}\right)$ at the time step, $t-1$, yielding the vertical stimulus sources at the current time step, $t$, of each tire for all vehicles; see equation (13).

(iii) The forces acting on each vehicle at the current time step $t$ induced by the vertical stimulus are calculated.

(iv) The vehicle subsystem in equation (11) is independently solved via the Newmark integration method to obtain the initial vehicle response $\left(\ddot{\mathbf{u}}_{v}^{t}, \dot{\mathbf{u}}_{v}^{t}, \mathbf{u}_{v}^{t}\right)$ at the current time step $t$.

(v) Solve the bridge responses at the current time step $t$.

(1) The wheel-bridge contact force at the current time step, $t$, can be determined according to the obtained vehicle responses.

(2) The load vector of the bridge is formed and the bridge subsystem in equation (12) is independently solved by the Newmark integration method and the current deformed position and internal forces are then obtained and updated.

(vi) The deck movements obtained in the step (v) are adopted for step (ii).

(vii) The steps from (ii) to (vi) are repeated until the geometric compatibility and force equilibrium conditions at the wheel-bridge contact points are satisfied and then the calculations continue for the next time step, $t+1$.

It is noteworthy that a grillage VBI model has been developed by the coauthor following similar procedure except that the bridge is modeled by the grillage method with beam elements. The grillage model has been successfully applied to investigate the bridge behavior including displacement and internal force under dynamic vehicle load $[3,20]$ and is selected here as a compared counterpart of the present solid VBI model.

\section{Validation of Solid Vehicle-Bridge Interaction Model}

The solid VBI model established in Section 2 is validated through a case study on a simply supported T-girder bridge. 
3.1. Description of Prototype Bridge. A prefabricated simply supported T-girder bridge with a span length of $30 \mathrm{~m}$ (PCT30 ), which represents the majority of concrete bridges in China, is considered here. The mid-span cross-section of PCT-30 is depicted in Figure 5. The bridge consists of five identical prestressed T-girders with uniform spacing of $2.35 \mathrm{~m}$. Besides the end diaphragms, the other three intermediate diaphragms are also used to connect the five girders.

3.2. Field Test. Both static and dynamic tests were conducted on the bridge. Two dump trucks, i.e., Truck-A and Truck-B, were used for loading. The detailed information of two trucks is given in Figure 6(a), where the axle weights were obtained in advance from a weighing system. The static test included two loading scenarios: (1) symmetrical loading of two dump trucks; (2) eccentric loading of two dump trucks, as illustrated in Figure 6(b). The longitudinal truck position in both scenarios was determined to yield the maximum displacement at the mid-span. The dynamic test considered the pass of Truck-A along the bridge center line at a uniform speed of $30 \mathrm{~km} / \mathrm{h}$, as shown in Figure 6(c), where GVW denotes the gross vehicle weight.

The bridge was equipped with displacement, strain and acceleration transducers to collect the bridge responses at the selected points that were expected to be significant. Displacements were measured independently at the five points located on the mid-span bottom surfaces of five girders, as shown in Figure 6(b). Strains were also measured at the same points as those of displacements, and stresses were obtained from those strain readings using the onedimensional linear stress-strain relationship. Acceleration histories were collected for the bridge using six accelerometers symmetrically instrumented on the $L / 4, L / 2$, and $3 \mathrm{~L} / 4$ ( $L$ denotes the span length) as shown in Figure 6(c). Readings of acceleration histories at the free vibration stage when the Truck-A had left the bridge were used for modal analysis of the bridge.

3.3. Bridge FE Model. Based on the configuration of the bridge, a numerical model is established and shown in Figure $7(\mathrm{a})$. The structural components including main girders, diaphragms and barriers are all modeled using the incompatible solid element, ICH8. The prestressed tendons are not independently modeled whereas the prestressing effect is taken into consideration by modifying the elastic modulus of the concrete girders in the subsequent model updating process [21]. The cast-in-place joint is treated as part of the flange plate of T-girder due to its near-perfect connection stiffness. As ICH8 element is restrained from shear locking, only two layers of elements are distributed along the thickness direction of the bridge deck. Totally 7236 solid elements and 32797 nodes are involved in the bridge FE model. To better demonstrate the validity as well as superiority of the developed solid VBI model, the grillage model of the bridge is also built using 280 two-node beam elements as shown in Figure 7(b). Design values of concrete material properties in both bridge models are provided in Table 1.

3.4. Model Updating. The deviation of FE model to field measured result is mainly attributed to various simplifications and approximations on the material parameters, the physical dimensions of the structure and the boundary conditions in the FE model $[22,23]$. Here, the boundary condition and the concrete material parameters including elastic modulus and density in solid and grillage bridge models are corrected according to the field measured results. The three-axle vehicle model in Figure 3 is used to simulate the two dump trucks given in Figure 6(a) and the mechanical properties which have been provided in [19] are not given here due to space limitation.

3.4.1. Boundary Conditions. It is indicated in [9] that the design boundary conditions of bridge are sometimes not fully realized due to the actual situation of bearing and expansion joint. In order to determine the correct boundary conditions for FE models, eigenvalue analyses are conducted for four configurations of boundary condition listed in Table 2, where Case 1 refers to the design boundary condition. Axes $x, y$, and $z$ denote the longitudinal, transverse and vertical directions of the bridge, respectively. $U_{i}$ and $R_{i}$ are the translation and rotation along the $i$-axis, respectively. Since there are only three translational DOFs per node for solid element, Case 1 and Case 2 are considered for the solid FE model while all the four cases are considered for the grillage model. The computed first vertical bending mode, first torsional mode and second vertical bending mode under each case of boundary condition are compared with the corresponding measured frequencies in Table 3. It is found that, for both grillage and solid model, the design boundary condition shows the best agreement with the actual condition.

3.4.2. Material Parameters of Concrete. Because of uncertainty, the elastic modulus and density of girders and diaphragms, i.e., $E_{\mathrm{G}}, \rho_{\mathrm{G}}, E_{\mathrm{D}}$ and $\rho_{\mathrm{D}}$, are selected as updating variables, among which modifying elastic modulus of concrete can take into consideration the prestressing effect [21]. The four parameters take initial values as the corresponding design values given in Table 1 and then updated according to the bridge responses obtained from both static and dynamic test, with the objective function:

$$
f_{\text {obj }}=\underbrace{\sum_{i=1}^{2 \times n_{\mathrm{d}}} \chi_{i}\left(w_{\mathrm{c}}^{i} / w_{\mathrm{t}}^{i}-1\right)^{2}}_{\text {static }}+\underbrace{\sum_{j=1}^{3} \alpha_{j}\left(f_{\mathrm{c}}^{j} / f_{\mathrm{t}}^{j}-1\right)^{2}+\sum_{j=1}^{3} \beta_{j}\left(1 / \sqrt{\mathbf{M A C}_{j j}}-1\right)^{2}}_{\text {dynamic }},
$$




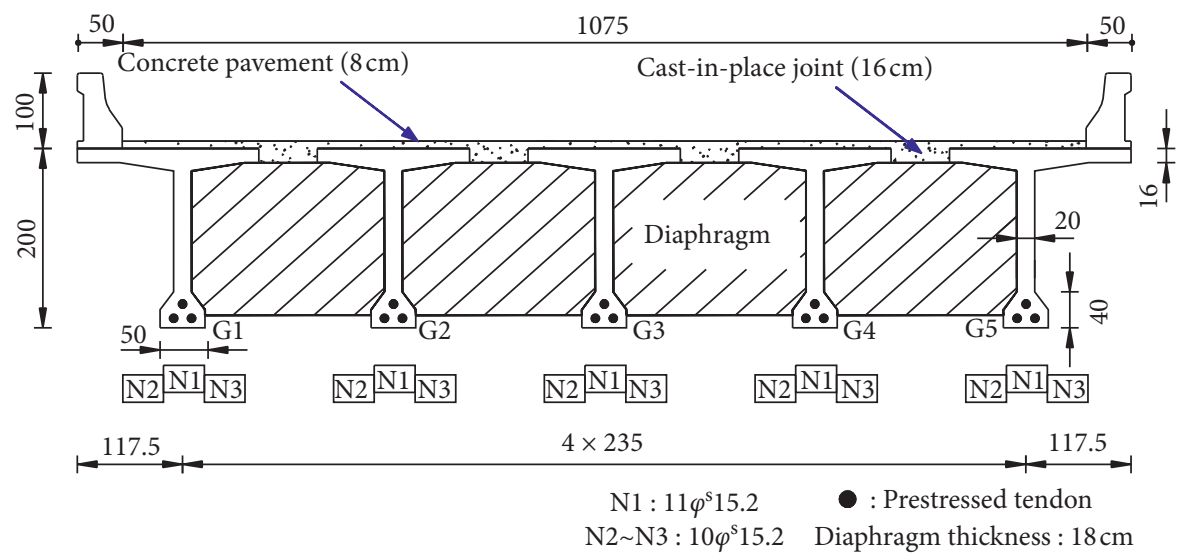

Figure 5: Mid-span cross-section of prototype bridge PCT-30 (unit: $\mathrm{cm}$ ).

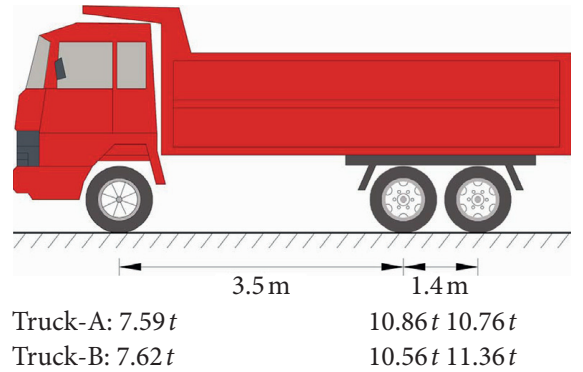

Truck-B: $7.62 t$

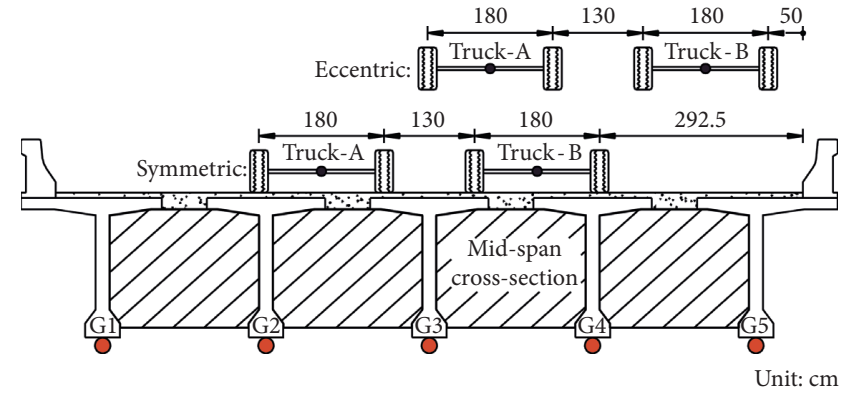

Displacement/strain transducers

(b)

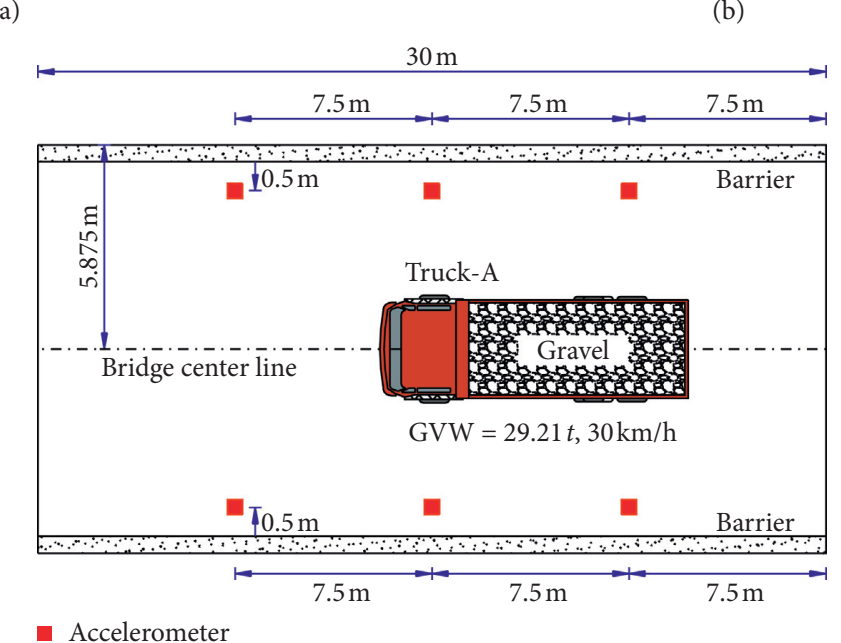

(c)

FIGURE 6: Field test setup: (a) detailed information of dump trucks; (b) loading scenarios in static test; (c) loading scenarios in dynamic test.

where $w_{\mathrm{t}}^{i}$ are measured vertical displacements under two loading scenarios in static test; $f_{\mathrm{t}}^{j}$ are the measured natural frequencies given in Table $3 ; w_{\mathrm{c}}^{i}$ and $f_{\mathrm{c}}^{j}$ are correspondingly the computed responses; $\mathrm{MAC}_{j j}=\left|\left(\varphi_{\mathrm{t}}^{j}\right)^{T} \varphi_{\mathrm{c}}^{j}\right|^{2} /\left\{\left[\left(\varphi_{\mathrm{t}}^{j}\right)^{T} \varphi_{\mathrm{t}}^{j}\right]\left[\left(\varphi_{\mathrm{c}}^{j}\right)\right.\right.$ $\left.{ }^{T} \varphi_{\mathrm{c}}^{j}\right]$ \}denotes the modal assurance criteria [6] between the $j$ th measured mode $\varphi_{\mathrm{t}}$ and the $j$-th computed mode $\varphi_{c} ; \chi_{i}, \alpha_{j}$ and $\beta_{j}$ are weight factors to define the importance level of each residual term and are all taken as unity; $n_{\mathrm{d}}=5$ is the total number of measured positions for displacement. The genetic algorithm [6] is implemented to resolve a set of parameters that minimize the objective function in equation (16) within a prescribed allowable tolerance, i.e., $\left|f_{\text {static }}^{k}-f_{\text {static }}^{k-1}\right| \leq 10^{-5}$. For reasonable updating results, it is prescribed that the change percent for $E_{\mathrm{G}}$ and $E_{\mathrm{D}}$ is within $-5 \%$ and $+20 \%$ whilst the absolute change percent for $\rho_{\mathrm{G}}$ and $\rho_{\mathrm{D}}$ is within $2 \%$.

The measured and computed vertical displacements before and after updating for two static loading scenarios are 

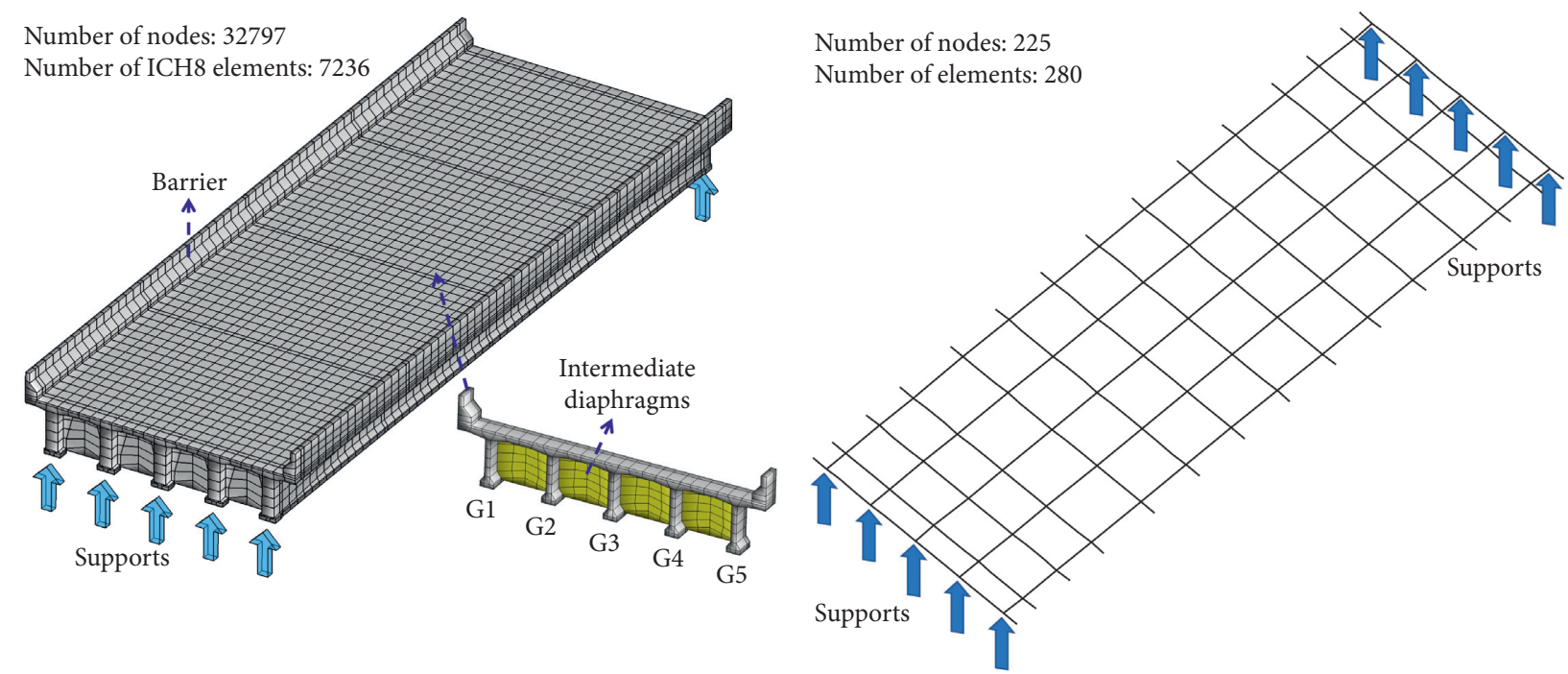

(a)

(b)

Figure 7: Bridge FE models: (a) solid FE model; (b) grillage model.

TABle 1: Design material parameters in bridge FE models.

\begin{tabular}{lccc}
\hline Notation & Parameter & Unit & Design value \\
\hline$E_{\mathrm{G}}$ & Elastic modulus of girders & $\mathrm{GPa}$ & 34.5 \\
$\rho_{\mathrm{G}}$ & Mass density of girders & $\mathrm{kg} / \mathrm{m}^{3}$ & 2549 \\
$E_{\mathrm{D}}$ & Elastic modulus of diaphragms & $\mathrm{GPa}$ & 34.5 \\
$\rho_{\mathrm{D}}$ & Mass density of diaphragms & $\mathrm{kg} / \mathrm{m}^{3}$ & 2549 \\
$E_{\mathrm{B}}$ & Elastic modulus of barriers & $\mathrm{GPa}$ & 34.5 \\
$\rho_{\mathrm{B}}$ & Mass density of barriers & $\mathrm{kg} / \mathrm{m}^{3}$ & 2549 \\
$\nu$ & Poisson's ratio of concrete & 0.2 \\
\hline
\end{tabular}

TABLE 2: Boundary conditions.

\begin{tabular}{lcc}
\hline & Left-side supports & Right-side supports \\
\hline Case 1 (design) & $U_{x}, U_{y}$ and $U_{z}$ constrained & $U_{y}$ and $U_{z}$ constrained \\
Case 2 & $U_{x}, U_{y}$ and $U_{z}$ constrained & $U_{x}, U_{y}$ and $U_{z}$ constrained \\
Case 3 (for grillage model only) & $U_{x}, U_{y}, U_{z}, R_{x}, R_{y}$ and $R_{z}$ constrained & $U_{y}, U_{z}, R_{x}, R_{y}$ and $R_{z}$ constrained \\
Case 4 (for grillage model only) & $U_{x}, U_{y}, U_{z}, R_{x}, R_{y}$ and $R_{z}$ constrained & $U_{x}, U_{y}, U_{z}, R_{x}, R_{y}$ and $R_{z}$ constrained \\
\hline
\end{tabular}

TABle 3: Computed and measured natural frequencies (unit: $\mathrm{Hz}$ ).

\begin{tabular}{|c|c|c|c|c|c|c|}
\hline Modes & Measured & FE model & Case 1 & Case 2 & Case 3 & Case 4 \\
\hline \multirow{2}{*}{$1^{\text {st }}$ vertical bending } & \multirow{2}{*}{4.81} & Solid & 4.61 & 7.79 & \multirow[t]{2}{*}{10.33} & \multirow[t]{2}{*}{10.33} \\
\hline & & Grillage & 4.53 & 4.53 & & \\
\hline \multirow{2}{*}{$1^{\text {st }}$ torsion } & \multirow{2}{*}{7.14} & Solid & 6.77 & 7.92 & \multirow[t]{2}{*}{10.90} & \multirow[t]{2}{*}{10.90} \\
\hline & & Grillage & 6.71 & 6.71 & & \\
\hline \multirow{2}{*}{$2^{\text {nd }}$ vertical bending } & \multirow{2}{*}{16.03} & Solid & 14.89 & 15.81 & \multirow[t]{2}{*}{27.89} & \multirow[t]{2}{*}{27.89} \\
\hline & & Grillage & 14.93 & 14.93 & & \\
\hline
\end{tabular}

compared in Figure 8. It can be seen that the computed vertical displacements from the updated bridge FE models agree well with the measured results for both loading scenarios. Meanwhile, the natural frequencies and correlation of mode shapes are also compared in Table 4 . The differences between FE and measured frequencies are reduced below
$1.61 \%$ and $3.45 \%$ for solid and grillage models, respectively, and the correlations of mode shapes are also well improved, higher than 92\% and 90\% for solid and grillage models, respectively, which is a significant improvement for the subsequent dynamic analysis of vehicle-bridge interaction. Besides, both static and dynamic results of the updated solid 


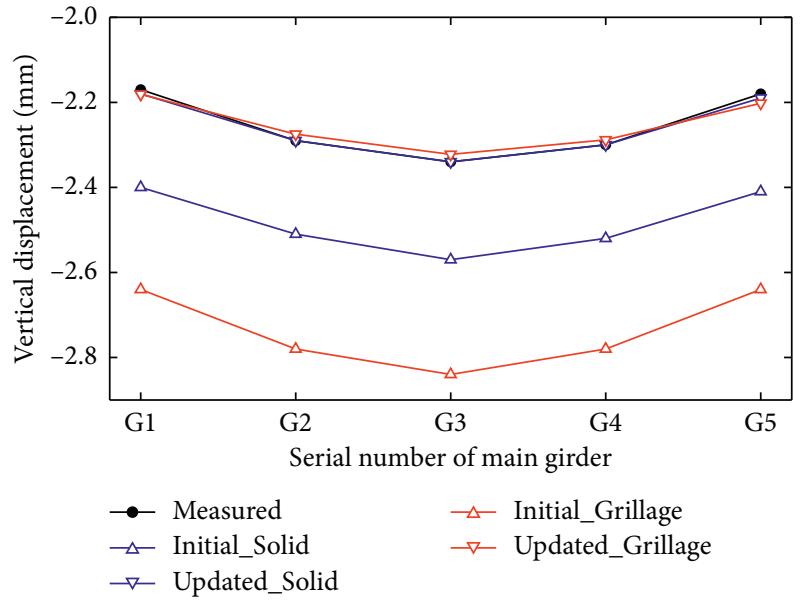

(a)

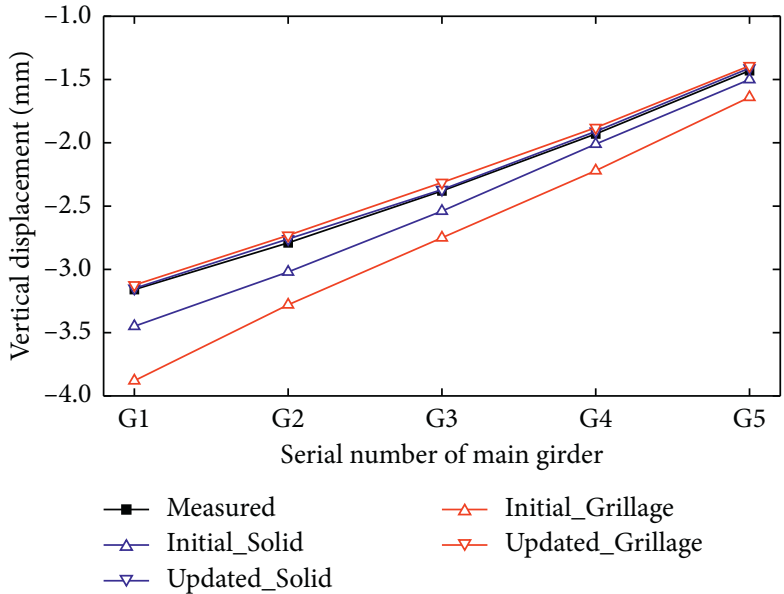

(b)

FIGURE 8: Vertical displacements at the five measuring points under (a) symmetric loading and (b) eccentric loading.

TABLe 4: Modal parameters of the solid (grillage) bridge FE model before and after updating.

\begin{tabular}{|c|c|c|c|c|c|c|c|}
\hline \multirow{2}{*}{ Modes } & \multicolumn{3}{|c|}{ Frequency $(\mathrm{Hz})$} & \multicolumn{2}{|c|}{ Frequency error (\%) } & \multicolumn{2}{|c|}{ MAC values (\%) } \\
\hline & Initial & Updated & Measured & Initial & Updated & Initial & Updated \\
\hline $1^{\text {st }}$ vertical bending & $4.61(4.53)$ & $4.86(4.71)$ & 4.81 & $4.29(5.82)$ & $-1.04(2.08)$ & $99.9(99.9)$ & $99.9(99.9)$ \\
\hline $1^{\text {st }}$ torsion & $6.77(6.71)$ & $7.08(6.89)$ & 7.14 & $5.23(6.05)$ & $0.84(3.45)$ & $96.5(86.5)$ & $98.9(90.5)$ \\
\hline $2^{\text {nd }}$ vertical bending & $14.89(14.93)$ & $15.77(15.65)$ & 16.03 & $7.09(6.84)$ & $1.61(2.37)$ & $89.4(82.3)$ & $92.3(89.6)$ \\
\hline
\end{tabular}

bridge model are closer to the measured results than that of grillage counterpart, which indicates the solid element can approximate the real structure with higher accuracy than the beam element.

The material parameters before and after updating are compared in Table 5. To check the physical meaning of the updated parameters, it can be found from Figure 8 and Table 4 that the computed deflections and frequencies from both initial FE models are larger than the corresponding measured values, indicating the initial $\mathrm{FE}$ models are less rigid than the real bridge. From Table 5, an increase in the value of stiffnessrelated parameters (elastic modulus) of main girders is accordingly observed while the values of mass-related parameters (density) are scarcely changed, as expected.

3.5. VBI Analysis of the Bridge. With the updated bridge FE models, dynamic analysis on PCT-30 subjected to a Truck-A travelling along the bridge center line at a uniform speed of $30 \mathrm{~km} / \mathrm{h}$ is conducted using the developed solid VBI model and the grillage VBI model. To better fulfill the real condition, the road surface roughness of the bridge has been measured and is depicted in Figure 9(a). The power spectral density (PSD) based on the measured road surface roughness is generated and compared to the three PSD curves corresponding to ISO levels, i.e., "Very good," "Good," and "Average," as shown in Figure 9(b). It is found that the overall road surface condition of PCT-30 is between "Good" and "Average."

The computed time-history vertical displacements and bending stresses at the five points located in the mid-span
TABLE 5: Material parameters before and after updating.

\begin{tabular}{lccccc}
\hline \multirow{2}{*}{ Parameters } & \multirow{2}{*}{ Initial values } & \multicolumn{2}{c}{ Updated values } & \multicolumn{2}{c}{ Change (\%) } \\
& & Solid & Grillage & Solid & Grillage \\
\hline$E_{\mathrm{G}}(\mathrm{GPa})$ & 34.5 & 38.8 & 41.3 & 12.46 & 19.71 \\
$E_{\mathrm{D}}(\mathrm{GPa})$ & 34.5 & 33.1 & 32.8 & -4.06 & -4.93 \\
$\rho_{\mathrm{G}}\left(\mathrm{kg} / \mathrm{m}^{3}\right)$ & 2549 & 2503 & 2589 & -1.80 & 1.55 \\
$\rho_{\mathrm{D}}\left(\mathrm{kg} / \mathrm{m}^{3}\right)$ & 2549 & 2563 & 2545 & 0.53 & -0.14 \\
\hline
\end{tabular}

bottom of the five T-girders are compared to the measured results from the dynamic test in Section 3.2. The stress of the solid VBI model is computed by nodal displacement via strain-displacement and stress-strain relations given in Section 2.1. The measured stress is obtained from the strain reading in dynamic field test using the one-dimensional linear stress-strain relationship. It is worth mentioning that the stress result of the grillage VBI model is calculated via the stress formula of pure bending theory because the bending moment on the cross-section containing node is the direct output from the grillage model. The result of the middle girder G3 is shown in Figure 10 as an example. It can be seen that the computed vertical displacement and bending stress generally agree well with the measurements except for larger fluctuations of the computed results at some time instants which might be induced by the deviation between the measured and the real road surface condition, data processing on the measured results, approximations on the dynamic characteristics of vehicle model, etc.

Furthermore, the bending stress at the top line of midspan cross-section when the front wheels of the truck is travelling to $L / 4$, i.e., $t=0.9 \mathrm{~s}$, is computed using both VBI 


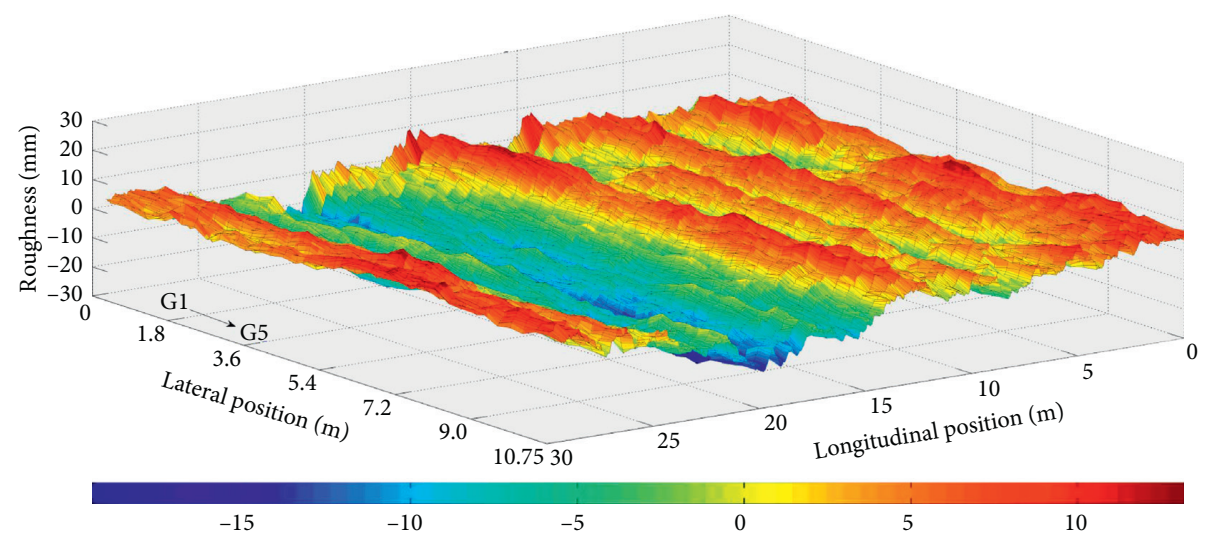

(a)

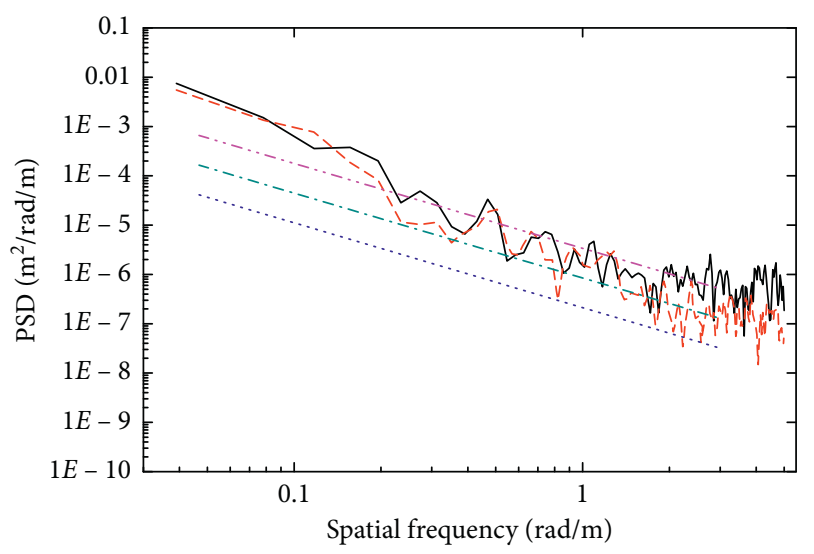

_ Center line of
carriageway
$\ldots \ldots$

(b)

FIGURE 9: Road surface condition of PCT-30: (a) surface roughness samples; (b) power spectral density (PSD).

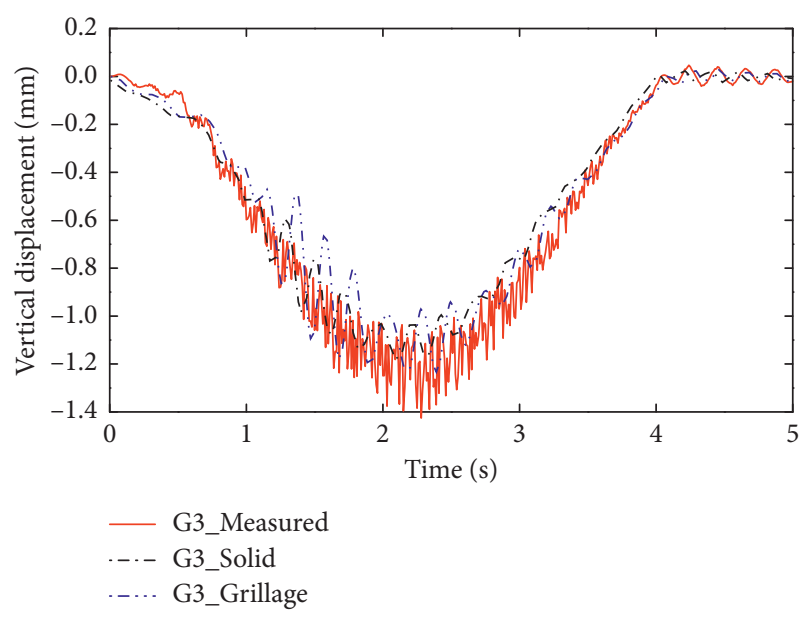

(a)

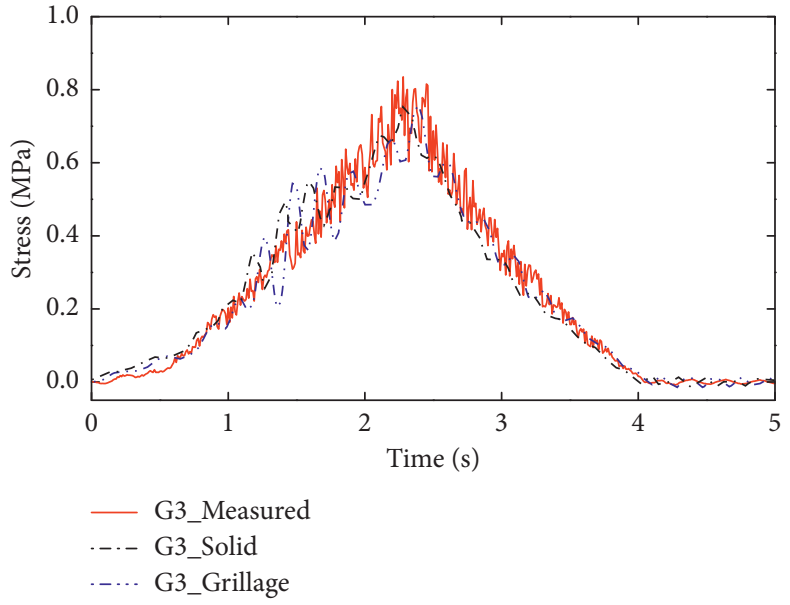

(b)

FIgURE 10: (a) Vertical displacement and (b) bending stress for the middle girder G3. 
models and depicted in Figure 11(a). It can be seen that the bending stress obtained from the solid VBI model increases smoothly from the side girder to the middle girder, which shows reasonable variation as in the real situation. By contrast the stress obtained from the grillage model remains uniform in each girder and sharp stress change which should be avoided in engineering practice is obviously observed at the interface between girders, for the reason that the grillage model can only produce the overall internal force at the cross-section of each girder rather than the stress distribution.

The stress distributions in local components are also simulated by the solid VBI model. Figure 11(b) shows the bending stress distribution in web plates when the front wheels of the truck are just travelling to the mid-span $(L / 2)$, i.e., $t=1.8 \mathrm{~s}$. It can be seen that overall the stress increases from both ends to the mid-span; the value seems to be reduced at the position where the diaphragm is located to enhance the stiffness of girders; stress concentration is also observed at these locations.

\section{Dynamic Impact Factor Spectrum of Bridge under Random Traffic Flow}

In most of the existing researches, the DIF is traditionally calculated from the bridge responses in displacement or bending moment and some researchers also argued that the DIFs calculated using different bridge responses are different and thus should be treated differently [24, 25]. To the authors' best knowledge, the DIF based on the load effect of stress is rarely reported. With the validated solid VBI model, the stress-based DIF of the prototype bridge, PCT-30, is investigated. The vehicle load characteristics of different vehicle category and the traffic loading scenarios are first obtained based on the monitored traffic data. The static and dynamic bending stresses at the mid-span bottom concrete of the girder G3 under each loading scenario are then computed by the solid VBI model with the measured road surface condition shown in Figure 9. The DIFs are calculated based on the computed static and dynamic bending stresses and the DIF spectrum of each vehicle category is investigated and compared to code values.

4.1. Traffic Data. The traffic data of G104 highway in Shaoxing, China, was monitored using the weigh-in-motion (WIM) equipment and the vehicle load characteristics including the classification of vehicle type were also investigated in previous research of the authors [26]. Here, the WIM data recorded in May 13, 2013, i.e., 5338 sets of vehicle data, is employed to analyze the DIF spectrum of PCT-30 under random traffic flow.

Figure 12(a) shows the traffic volumes of the 24 time blocks of May 13, 2013, in which the $1^{\text {st }}$ time block corresponds to the time interval from 0:00 am to 1:00 am and similarly the $24^{\text {th }}$ time block corresponds to the time interval from 11:00 pm to 0:00 am. Two traffic volume peaks located at the $10^{\text {th }}$ and the $17^{\text {th }}$ time block with the values 342 and 405, respectively, are observed in Figure 12(a). A local minimum value obviously appears in the $12^{\text {th }}$ time block for the potential reason that the corresponding time interval is just the lunch time. According to the previous research [26], the vehicle types of highway transportation can be merged into the following five categories:

Category-I: passenger cars, pickups, etc.

Category-II: medium-scale buses and medium-scale 2axle trucks

Category-III: Large-scale buses and large-scale 2-axle trucks

Category -IV: single unit 3-axle and 4-axle trucks

Category-V: single trailer trucks

Figure 12(b) shows the percentages of the five categories of vehicles. It can be seen that the vehicle quantity of Category-I is the highest, occupying $56.2 \%$, whereas the quantity of Category-II is the lowest, occupying only $7.6 \%$.

4.2. Random Traffic Flow Based on WIM Data. The traffic loading scenarios are extracted according to the recorded velocity and arriving time of vehicles as well as the span length of the prototype bridge, in which all vehicles simultaneously loading on the prototype bridge are merged into one individual loading scenario [26]. Totally 4926 loading scenarios are generated, including 4514 single-vehicle loading scenarios and 412 double-vehicle loading scenarios. The detailed information of each loading scenario including the vehicle weight, velocity, and lateral position is determined according to the recorded WIM data.

4.3. Dynamic Impact Factor Spectrum. The simulations of 4926 traffic loading scenarios are conducted using the developed solid VBI model to investigate the static and dynamic stress responses at the mid-span bottom concrete of the girder G3 with the measured road surface condition shown in Figure 9. Then, the DIF for each traffic loading scenario is calculated according to the computed stress results.

4.3.1. Dynamic Impact Factor Spectrum of the Five Vehicle Categories. The DIF samples with respect to each vehicle category are obtained and the fitting analysis results are depicted in Figure 13. The samples of Category-II and Category-III are merged in the analysis because the former is relatively small. As indicated in Figure 13, the DIF distributions of the five vehicle categories can be described by extreme-I distribution or normal distribution. The 95 percentile points of the DIF distribution, i.e., $\mathrm{DIF}_{0.95}$, are also provided in Figure 13. The $\mathrm{DIF}_{0.95}$ of Category-I is the highest with the value of 0.448 , whilst the $\mathrm{DIF}_{0.95}$ of Category- $\mathrm{V}$ is the lowest and its value is 0.207 .

\subsubsection{Dynamic Impact Factor Spectrum of Heavy Vehicles.} In China, the gross vehicle weight of $20 \mathrm{t}$ is frequently taken to define heavy vehicles. Here, the traffic loading scenarios with a vehicle heavier than $20 \mathrm{t}$ are selected and the sample 


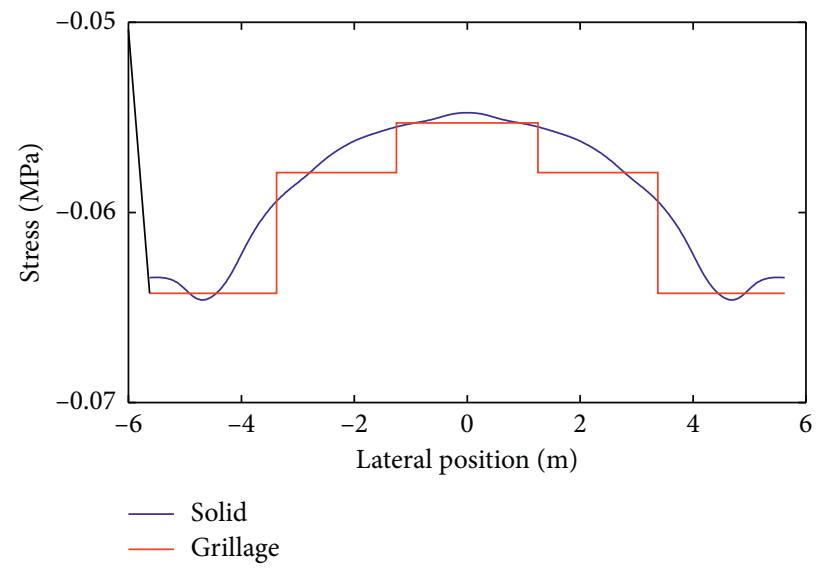

(a)
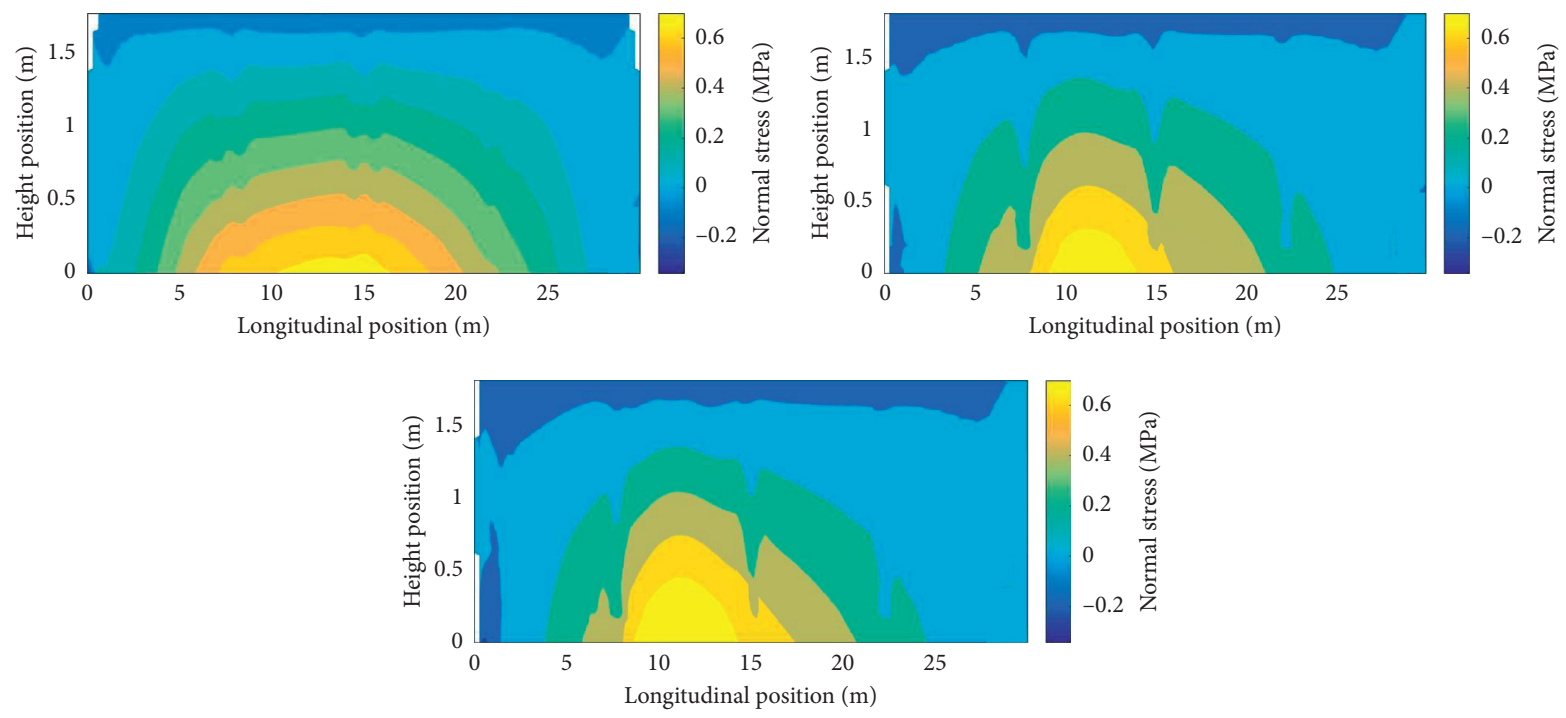

(b)

FIgURE 11: Bending stress distribution (a) at the top line of mid-span cross-section at $t=0.9 \mathrm{~s}$ and (b) in the web plates (from G1 [top] to G3 [bottom]) at $t=1.8 \mathrm{~s}$.

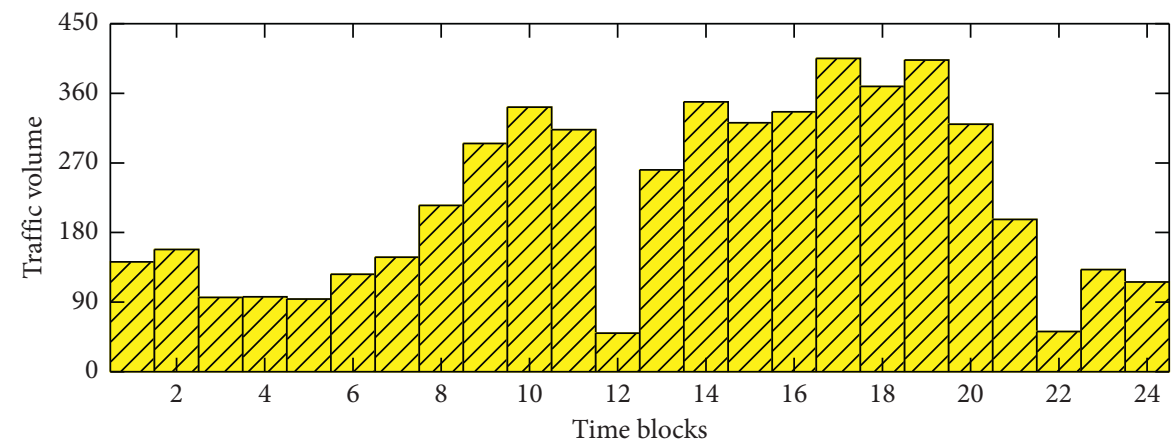

(a)

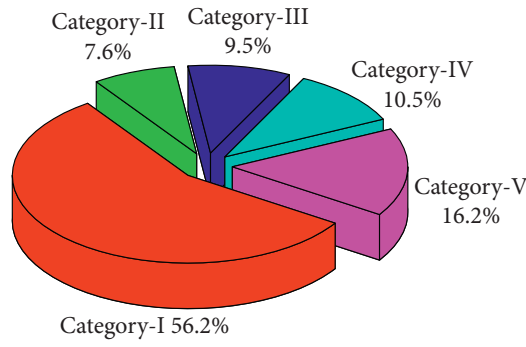

(b)

Figure 12: Monitored traffic data: (a) traffic volume; (b) percentages of vehicle categories.

analysis of corresponding DIF is depicted in Figure 14. It can be seen that the DIF of heavy vehicles can be described by extreme-I distribution and the resulting $\mathrm{DIF}_{0.95}$ is 0.279 .
4.3.3. Comparison with the Code Values. The $\mathrm{DIF}_{0.95}$ of the five vehicle categories and the heavy vehicles are compared to the values from AASHTO and Chinese codes 


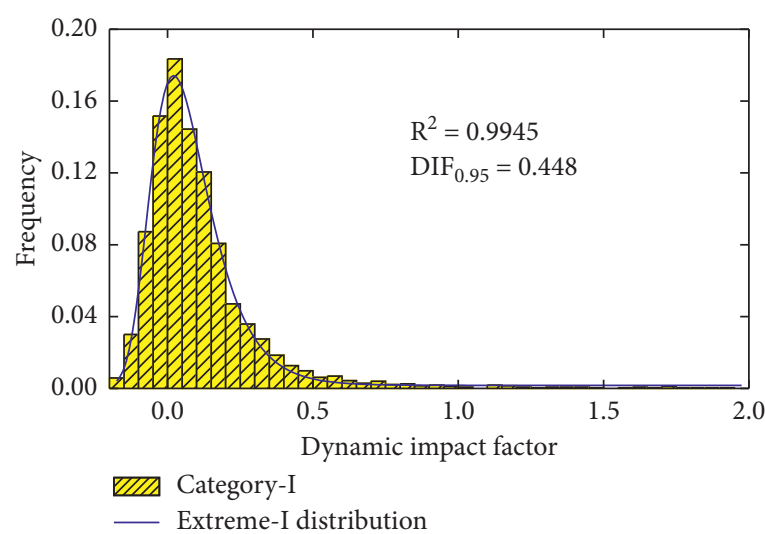

(a)

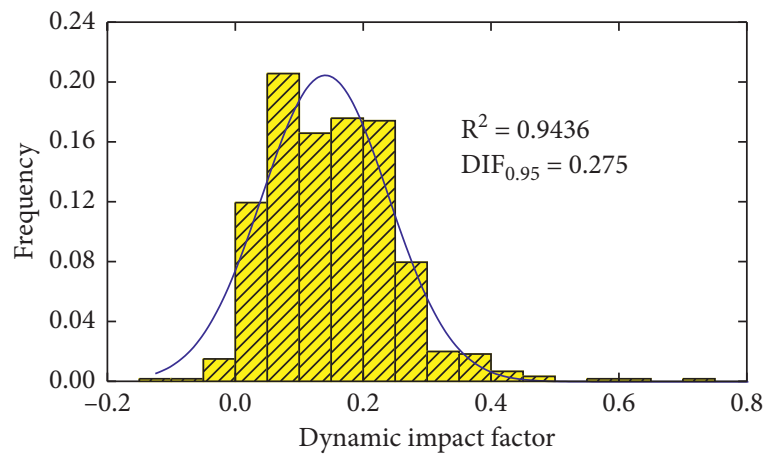

VIIA Category-IV

— Normal distribution

(c)

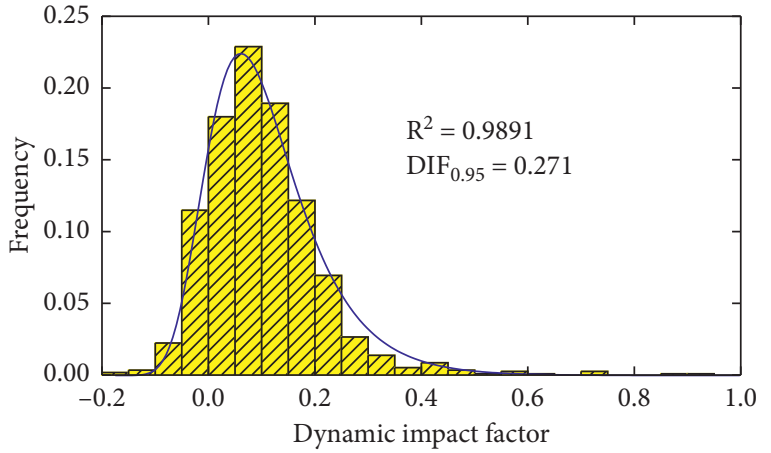

VIIA Category-II/III

- Extreme-I distribution

(b)

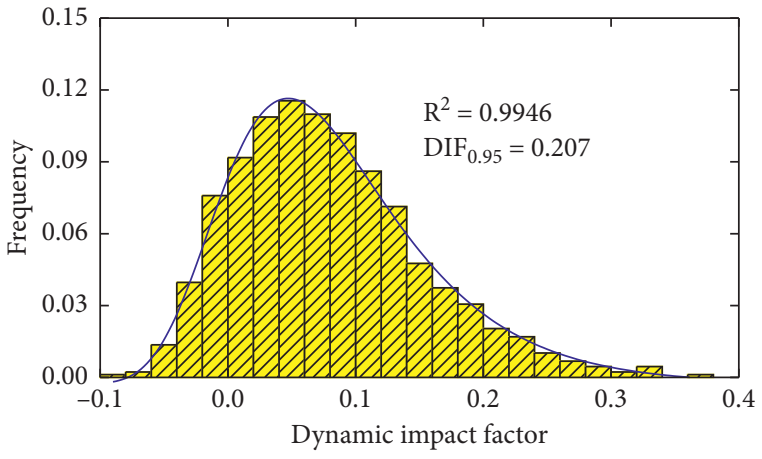

VII Category-V

Extreme-I distribution

(d)

FIgure 13: Dynamic impact factor spectrum with respect to (a) Category-I, (b) Category-II and Category-III, (c) Category-IV, and (d) Category-V.

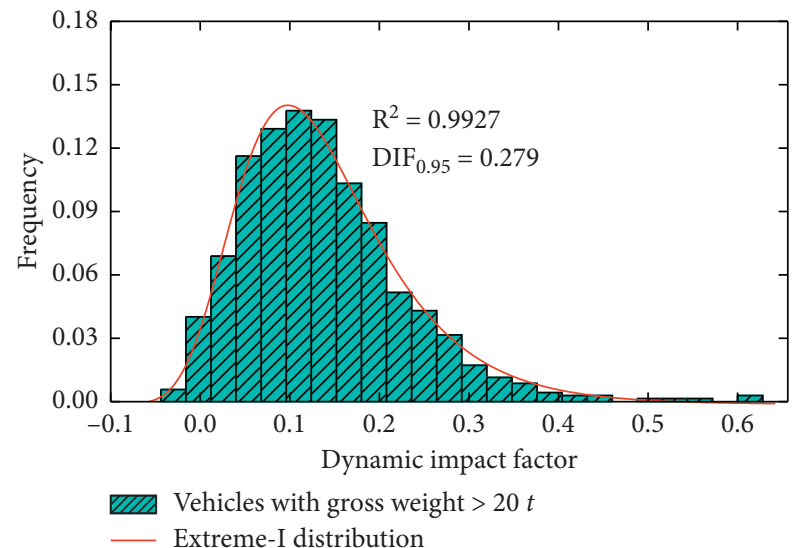

FIGURE 14: Dynamic impact factor spectrum of heavy vehicles.

$[27,28]$, as shown in Figure 15. Note that those code values are calculated based on the natural frequency or span length of PCT-30. It can be seen from Figure 15 that the $\mathrm{DIF}_{0.95}$ decreases for the vehicles from Category-I to Category- $\mathrm{V}$ for the underlying reason that the velocity usually decreases whilst the gross weight usually increases for vehicles from Category-I to Category-V. Moreover,

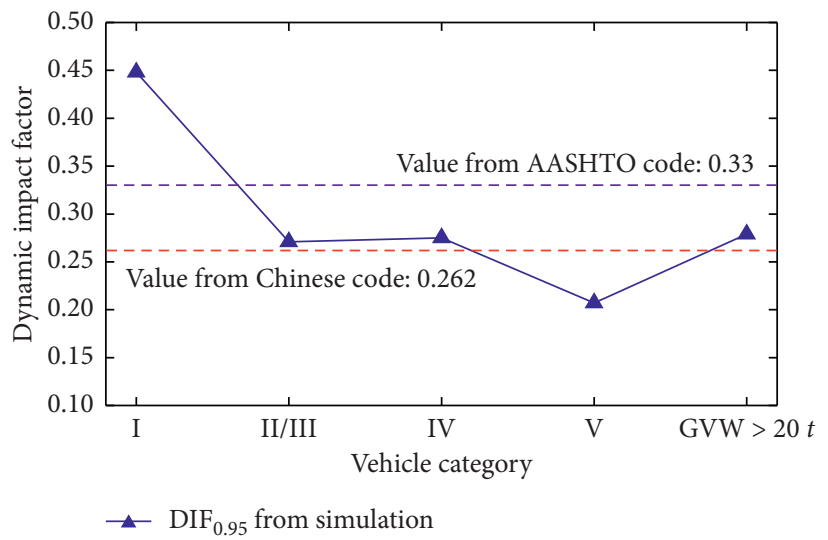

FIgURE 15: Comparison of dynamic impact factor with the code values.

the $\mathrm{DIF}_{0.95}$ of these vehicle categories generally conforms well to the code values except for that of Category-I. Besides, the $\mathrm{DIF}_{0.95}$ of heavy vehicles $(\mathrm{GVW}>20 \mathrm{t}$ ) is slightly higher than the value in Chinese code while lower than that of AASHTO, suggesting the value specified by Chinese code may underestimate the DIF of heavy vehicles in certain circumstances to which more attention is paid. 


\section{Conclusion}

In this paper, a solid VBI model is developed to provide full transient analysis on bridge responses including displacement and stress under random traffic loads. The incompatible solid finite element possesses higher computational efficiency than the conventional counterpart and thus is selected to model the bridge. Through the case study on a prototype bridge, PCT-30, the solid bridge model has better approximation on the real bridge and more accurate timehistory bridge responses including displacement and stress to moving vehicles are achieved directly from the solid VBI model, compared to the commonly used grillage VBI model. Specifically, the solid VBI model can simulate realistic stress distribution and concentration along any concerned sections as well as in local components, which can provide detailed information on the bridge structure behavior subjected to dynamic loads. The DIF of PCT-30 based on the stress results obtained from the validated solid VBI model is also investigated. According to the comparison with code values, it is found that the DIF based on the computed stress results generally agrees well with the code values except for heavy vehicles $(\mathrm{GVW}>20 \mathrm{t})$ where the stress-based DIF is slightly higher than the value in Chinese code while lower than that of AASHTO, suggesting the value specified by Chinese code may underestimate the DIF of heavy vehicles in certain circumstances to which more attention is paid.

It is further expected to introduce the reinforcement and pre-stressed steel models to the present solid VBI model so that the local performance of reinforcement and pre-stressed steel as well as their effects on the static and dynamic responses of the bridge structure can be better observed. The solid VBI model is expected to provide a more refined tool to investigate the performance of small-to-medium-span bridges under dynamic service loads.

\section{Data Availability}

The data used to support the findings of this study are included within the article.

\section{Conflicts of Interest}

The authors declare that they have no conflicts of interest.

\section{Acknowledgments}

This work was supported by the Natural Science Fund in Shaanxi Province (2018JQ5031), the Natural Science Fund of China (51878058), and the Fundamental Research Funds for the Central Universities, CHD (300102210101).

\section{References}

[1] C. S. Cai and S. R. Chen, "Framework of vehicle-bridge-wind dynamic analysis," Journal of Wind Engineering and Industrial Aerodynamics, vol. 92, no. 7-8, pp. 579-607, 2004.

[2] A. Gonzalez, Vehicle-Bridge Dynamic Interaction Using Finite Element Modelling, InTechOpen, London, UK, 2010.
[3] W. Han, Y. Yuan, X. Chen, Q. Xie, G. Gao, and J. Zhang, "Safety assessment of continuous beam bridges under overloaded customized transport vehicle load," Journal of Bridge Engineering, vol. 23, no. 6, Article ID 04018030, 2018.

[4] Y. Zhou and S. Chen, "Dynamic simulation of a long-span bridge-traffic system subjected to combined service and extreme loads," Journal of Structural Engineering, vol. 141, no. 9, Article ID 04014215, 2015.

[5] Q. Xie, Y. X. Zhou, Y. Zhan, K. Y. Sze, and W. S. Han, “A comparative study on the beam and continuum finite element models for the rail-wheel vibration," International Journal of Structural Stability and Dynamics, vol. 19, no. 7, Article ID 1950076, 2019.

[6] K. Nguyen, B. Freytag, M. Ralbovsky, and O. Rio, "Assessment of serviceability limit state of vibrations in the UHPFRC-Wild bridge through an updated FEM using vehicle-bridge interaction," Computers \& Structures, vol. 156, pp. 29-41, 2015.

[7] E. J. Obrien, D. Cantero, B. Enright, and A. González, "Characteristic dynamic increment for extreme traffic loading events on short and medium span highway bridges," Engineering Structures, vol. 32, no. 12, pp. 3827-3835, 2010.

[8] J. Malveiro, D. Ribeiro, C. Sousa, and R. Calçada, "Model updating of a dynamic model of a composite steel-concrete railway viaduct based on experimental tests," Engineering Structures, vol. 164, pp. 40-52, 2018.

[9] J.-C. Wyss, Y. Su, and Y. Fujino, "Prediction of vehicle-induced local responses and application to a skewed girder bridge," Engineering Structures, vol. 33, no. 4, pp. 1088-1097, 2011.

[10] L. Kwasniewski, H. Li, J. Wekezer, and J. Malachowski, "Finite element analysis of vehicle-bridge interaction," Finite Elements in Analysis and Design, vol. 42, no. 11, pp. 950-959, 2006.

[11] X. Yin, C. S. Fang, and C. S. Cai, "Lateral vibration of highpier bridges under moving vehicular loads," Journal of Bridge Engineering, vol. 16, no. 3, pp. 400-412, 2011.

[12] Q. Zou, L. Deng, T. Guo, and X. Yin, "Comparative study of different numerical models for vehicle-bridge interaction analysis," International Journal of Structural Stability and Dynamics, vol. 16, no. 9, Article ID 1550057, 2016.

[13] J. Argyris, "An excursion into large rotations," Computer Methods in Applied Mechanics and Engineering, vol. 32, no. 1-3, pp. 85-155, 1982.

[14] Q. Xie, Y. X. Sze, and Y. X. Zhou, "Modified and Trefftz unsymmetric finite element models," International Journal of Mechanics and Materials in Design, vol. 12, no. 1, pp. 53-70, 2016.

[15] Q. Xie, Y. X. Sze, and Y. X. Zhou, "Drape simulation using solid-shell elements and adaptive mesh subdivision," Finite Elements in Analysis and Design, vol. 106, pp. 85-102, 2015.

[16] K. Y. Sze, "Three-dimensional continuum finite element models for plate/shell analysis," Progress in Structural Engineering and Materials, vol. 4, no. 4, pp. 400-407, 2002.

[17] E. L. Wilson, R. L. Taylor, W. P. Doherty et al., "Incompatible displacement models," in Numerical and Computer Methods in Structural Mechanics, pp. 43-57, Academic Press, New York, NY, USA, 1973.

[18] S. Timoshenko, S. Woinowsky-Krieger, and S. Woinowsky, Theory of Plates and Shells, McGraw-Hill, New York, NY, USA, 2nd edition, 1970.

[19] W. Han, L. Yuan, and L. Ma, "Vibration of vehicle-bridge coupling system with measured correlated road surface roughness," Structural Engineering and Mechanics, vol. 51, no. 2, pp. 315-331, 2014. 
[20] W. Han, J. Wu, C. S. Cai, and S. Chen, "Characteristics and dynamic impact of overloaded extra heavy trucks on typical highway bridges," Journal of Bridge Engineering, vol. 20, no. 2, 2015.

[21] L. Deng and C. S. Cai, "Bridge model updating using response surface method and genetic algorithm," Journal of Bridge Engineering, vol. 15, no. 5, pp. 553-564, 2010.

[22] H.-P. Wan and W.-X. Ren, "Parameter selection in finiteelement-model updating by global sensitivity analysis using Gaussian process metamodel," Journal of Structural Engineering, vol. 141, no. 6, Article ID 04014164, 2015.

[23] Y. Yuan, W. Han, P. Huang, J. Zhao, Y. Li, and J. Zhang, "Structure safety assessment under heavy traffic based on weigh in motion and simulation analysis," Advances in Structural Engineering, vol. 20, no. 12, pp. 1864-1878, 2017.

[24] L. Deng, Y. Yu, Q. Zou, and C. S. Cai, "State-of-the-art review of dynamic impact factors of highway bridges," Journal of Bridge Engineering, vol. 20, no. 5, 2015.

[25] M. Fafard, M. Laflamme, M. Savard, and M. Bennur, "Dynamic analysis of existing continuous bridge," Journal of Bridge Engineering, vol. 3, no. 1, pp. 28-37, 1998.

[26] W. Han, Y. Yuan, P. Huang, J. Wu, T. Wang, and H. Liu, "Dynamic impact of heavy traffic load on typical T-beam bridges based on WIM data," Journal of Performance of Constructed Facilities, vol. 31, no. 3, Article ID 04017001, 2017.

[27] AASHTO, LRFD Bridge Design Specifications, AASHTO, Washington, DC, USA, 2004.

[28] Ministry of Communications and Transportation (MOCAT), General Code for Design of Highway Bridges and Culverts (JTG D60-2015), MOCAT, Beijing, China, 2015. 